\title{
The characteristics and the communicative function of pronouns (Western and Eastern European languages)
}

\author{
Nataliia Epifantseva ${ }^{1, *}$, Anastasiia Baluta ${ }^{1}$, Svetlana Bukhtiiarova ${ }^{1}$, Alina Tsepeleva $^{1}$ \\ ${ }^{1}$ Moscow Region State University, Radio str., 10A, 105005, Moscow, Russia
}

\begin{abstract}
Grammatical and syntactic characteristics of pronouns are mainly considered based on the material of French grammatical system, which implemented the analytical tendencies of the Latin language in the course of evolution. It has been established that the major opposition in the pronominal system, that is the opposition of the 1 st and 2 nd person forms to the 3 rd person forms, is an important factor in the communicative function of pronouns. In the substitutive function, pronominal forms are distinguished by the presence of an antecedent: substitutes of the 3rd person as well as personal pronouns that are the substitutes of the 1st and 2nd person. It has been revealed that personal pronouns are independent and do not require the preliminary use of the substituted form. The syntactic function of pronouns as an indicator differentiating a simple/complex sentence has been noted. The communicative function of a pronoun has been particularly pointed out. Thus, the forms 'read, reads' in the context of indicating the grammatical person, could represent the sender/recipient/subject of communication, in this way implementing the function of the communicative role of the person in the speaking process. The results of the research allow to state that a pronoun, forming a complex system with oppositions of forms based on different principles, acts as a significant element of the communication process.
\end{abstract}

\section{Introduction}

In modern linguistics, the pronoun attracts scientific interest in such fields as discourse analysis, text theory, and other areas related to the communication activity of a person. The article analyzes and summarizes the views of national and foreign linguists on the grammatical and functional characteristics of pronouns in Western European languages, mainly using the example of the French language, which has implemented Latin analytical trends, and the Russian language with a predominantly synthetic structure.

A French finite verb is actualized by endings, auxiliary verbs, and pronouns-subjects that are so necessary that omitting a repeated pronoun in a sentence

*Paul et moi sommes amis is a deviation from the norm. In a segmented sentence, a stressed pronoun is necessarily repeated in the unstressed form when used with a verb, which also

\footnotetext{
* Corresponding author: taniasemina@gmail.com
} 
reveals the connection between them. The repetition of object pronouns in such cases is also mandatory.

\section{Materials and methods of the study}

The material of the article is the pronominal forms of the French language as a representative of Western European languages, which developed analytical tendencies of Latinism, and the pronouns of Russian, which is a mainly synthetic language. The methodological basis of the research is the position on the unity of a language and speech. Regarding the language as a sign system (a structure) used by a person in speech production involves its study in terms of the two aspects, namely, the grammatical aspect (when the language acts as a complex systematic phenomenon), and the speech aspect (when the language implements the function of speech communication). The theoretical basis of the research is the works of national and foreign authors, except those listed in the section "References", such as: Alferov A.B., Blokh M.Ia., Korpusova E.V. The descriptive analytical method applied in the study allowed to discover the characteristics of pronominal forms and present these forms as a system of oppositions, which function in accordance with the pragmatic objectives and conditions of speech communication.

\section{Results}

It has been established that the grammatical characteristics and status of the pronoun are interpreted differently by researchers. A pronoun is defined as the actualizer of a verb. A verb semanteme in French could not be actualized without grammatical indicators and endings. A pronoun is an actualizer of a verbal semanteme, its connection with the verb is necessary and inextricable. A pronoun is also defined as a noun substitute, which could be used in an anaphoric function. In case the anaphor corresponds with the form, the substitute is called definite. These are $3 \mathrm{rd}$ person pronouns that substitute an antecedent that does not cover the scope of the 1 st and 2 nd person.

Substitutes of the 1-st and 2-nd person, i.e. personal, are independent and do not require prior use of the substituted form. Both personal and definite substitutes form a closed system of personal-definite substitutes, which is supplemented by pronouns that are included in the pronominal forms of a verb. Bloomfield L. considers pronouns to be one of the types of substitutes [1]. A pronoun can only substitute forms of a certain class, i.e. each type of a substitute has a particular domain. A substitute has a general meaning that coincides with the class-meaning of its domain; a typical meaning, that is the circumstances under which the substitution takes place. A noun substitute is a pronoun.

Substitutes that replace a form that has recently appeared in a certain text are called anaphoric. This is the practical utility of substitutions, since in most cases substitutions are shorter than the substituted word, often unstressed, and more adapted to rapid speaking. Thus, anaphoric pronouns are substitutes which typical meaning is reduced to anaphora. In case the anaphor corresponds with the form, the substitute is called definite. These are 3rd person pronouns that substitute an antecedent that does not cover the scope of the 1 st and 2 nd person.

Moignet G. believes that in the French language, a pronoun exists as a separate category that replaces the nominal one in such cases where the use of the noun is impossible, or it overloads the speech. The use of the name is not possible when the speech covers the area of the 1-st or 2nd person. The name belongs to the sphere of the 3rd person (except for its use as an attribute). In order to avoid the sphere of the 3 rd person, it is necessary to use the pronouns je or $t u[2]$.

The pronominal form of the 3rd person does not solve the question of replacing the name, 
but eliminates stylistic inconveniences, and, in the expression il pleut, etc., it is considered to be the expression of the zero person. There is a notional correspondence between a name and the concept expressed by it (comprehension). The name represents the means by which this concept is perceived (apprehension). The means of perception correspond to the norms of a language system and differ in various languages. What is expressed in Latin by the form of the word itself is conveyed in French through specific forms of pronouns. It is also equally possible to use the name and pronoun, but in order to avoid repetition, a pronoun is used. In addition, a pronoun is applied to express an implication, avoiding a precise wording of the person. Finally, the pronoun is impersonal in the expressions such as il arrive, il pleut.

In some cases, the use of a pronoun is the only possible option, in certain instances, substituting the name for a pronoun is convenient and elegant. A pronoun could be called a real dematerialized name. The forms $m o i$, toi, and lui function as names, with minor features due to the presence of parallel verb forms. Syntactically, they are as independent as nouns. The main opposition in the system of pronouns is considered to be the opposition of autonomous and adverbial forms: the first belong to the sphere of a name, the second - to the sphere of a verb.

Jacobson R. refers a pronoun to the categories of a verb. In the language code, there is a particular class of grammatical units that could be called embrayeurs (translation of 'snifter' of Jespersen O.). Their meaning could only be determined with the connection to the context. The distinctive feature of personal pronouns lies in the fact that they do not convey the single and constant meaning. The same could be stated about the conjunction mais, which expresses the meaning of a contrast only when used in a sentence. Thus, the only distinction of embrayeurs from other elements of the language code arises from the fact that they necessarily correlate to the utterance [3].

In Russian linguistics, the problems concerning pronouns are still of great interest. In the works of Zolotova G.A., the role of pronouns in the sentence is studied [4]. The author considers pronouns from the perspective of the syntactic composition. The presence of a pronoun in a sentence with two or more predicates could serve as one of the form features differentiating a compound sentence and a combination of simple independent sentences.

In the modern Russian language, a simple independent sentence must include a verb and a personal subject pronoun (if the subject is not expressed by a noun). Therefore, the presence of a subject pronoun next to the second verb indicates that predicative units do not form a compound sentence. This feature is relevant for sentences with a common subject, which could be regarded as the most typical characteristic for a compound sentence.

In the question of monopredicativity, i.e., the distinction between a compound sentence and a sentence with homogeneous predicates, the use of a personal pronoun can serve as one of the differential features that distinguish these syntactic units. In modern French, a verb is accompanied with a personal pronoun. The situation in which a personal pronoun is not used can be considered one of the features of a sentence with homogeneous predicates. Although this feature alone might not be sufficient, since a pronoun may be absent for stylistic reasons. Other form features of monopredicativity may be means of communication, certain common characteristics of the verb (transitivity/intransitivity, semantic similarity), an disjunct adverbial modifier, or a common direct object. The disjunct construction (verb-object / verb-object) is peculiar to the French language. In case the object is expressed by a personal pronoun, the disjunction is considered to be mandatory. In such a construction, the presence of an object pronoun that expresses the same object would not be relevant. Thus, a personal pronoun is a structural feature of a certain type of syntactic units. The use of a personal pronoun depends on the type of syntactic units.

Gak V.G., in his work on object pronouns and clitic doubling, concludes that object pronouns express object relations of a verb in modern French. In the Russian phrase ' $э m y$ книгу, я ее читал' (this book, I have read it), the pronoun is syntactically superfluous. In the French language, which led the Roman tendency to analytism to its fullest development, a 
phrase without a doubling of a direct object with an object pronoun would be grammatically incorrect. In this case, the clitic doubling performs not only a stylistic, but also a grammatical function [5]. In modern French, unstressed object pronouns perform a syntactic function. These pronouns have become peculiar substitutes that fill in the parts of a sentence that are necessary for the verb, which are lexically expressed in another sentence, or act as a detached part. Initially, the distinction between stressed and unstressed pronouns in French was stylistic, the stressed form was used mainly for emphasis, and the unstressed form was applied when there was no special emphasis. In further development, from stylistic variants of stressed forms, unstressed pronouns transformed into important semantic and syntactic regulators of a sentence. An unstressed pronoun has not only remained, but also acquired a new function. In French, their role is purely syntactic - they are used as substitutes in the absence of a lexically expressed object.

As pleonastic usage develops, a pronoun loses its substitutive function, since it appears simultaneously with the object itself. This fact predetermines the morphologization of an object pronoun, which acts as a word that expresses the transitivity of a verb, and at the same time, the category of transitivity of the verbal object [6].

Isachenko A.B. approaches the problem of pronouns from the perspective of syntactic analysis [7]. The author suggests to regard certain pronouns in the Russian language as 'substitutes' from the point of view of their syntactic origin (only in synchronic terms, i.e. as a result of the transposition). By origin, the author implies the derivation of a construction from another one by applying certain rules in a certain order. As a result of the analysis of syntactic relations of certain types of pronouns, it could be concluded that it is not reasonable to select pronominal forms containing the particles ' $н е$ ', ' $н и$ ', 'кое' and some others as special morphological subclasses. These pronouns are associated with certain types of sentences, as well as a fixed word order in these sentences, and appear in them due to pronominalization. The author's conclusions coincide with the point of view of Vinogradov V.V., who refused to recognize a special class of pronouns on the basis of morphological and lexical-semantic criteria.

Personal pronouns in all languages function as a separate part of speech, since the peculiar morphological features of pronouns are determined by their nature. The category of personal pronouns is clearly distinguished only if the 2 nd person is regarded as opposed to the 1st person, since the sphere of the 3rd person can be expressed by demonstrative pronouns.

The 1st, 2nd person / 3rd person opposition has the following characteristics: the 1st and 2nd person are used when referencing to people, while the use of the 3rd person pronoun is possible when referencing to objects and people; the ways of forming the plural form of the 1 st and 2 nd person are different from the $3 \mathrm{rd}$ person (the suppletive method of formation is peculiar to the forms of the 1 st and 2 nd person, the 3 rd person is characterized by preserving the same root). However, certain authors who consider the pronouns 'I' and 'we', 'you' as independent, refuse to consider the presence of two different stems in these cases to be 'heteroclisis'. The forms of the 1 st and 2 nd person are opposed to the 3 rd person in terms of participation in a conversation, since the 1 st and 2 nd persons are directly involved in a conversation.

As for the declension of personal pronouns, in French it sharply differs from the declension of nouns. For instance, there are no special forms of a noun for the expression of objective case, however, there are special forms of pronouns, and the $3 \mathrm{rd}$ person pronoun is inflected for 3 cases - il, le, lui. According to the manner of production of the forms of objective cases, French pronouns are divided into the suppletive forms, that possess phonetic differences between the nominative and objective cases while maintaining the primary element of roots, and the forms that are the same for the nominative and objective cases.

In the speech-language aspect, pronouns are regarded as a particular type of language units that serve to refer to the act of speech in which they are used. The major characteristic of 
pronouns as deictic words is considered to be the ability to serve as a means of reference. The 1 st and 2 nd person pronouns are characterized by the function of deixis, i.e. the reference to such elements of the situation as the participants of the communication, time, place, and everything that relates to the act of speech. A function peculiar to forms of the 3rd person is the function of anaphora, that is the equivalence of an act of speech or its elements to another act of speech or its elements. However, these forms can also be used in deixis.

Pronominal forms are divided into two types - substitutes of persons and objects and substitutes of events. A subject form of a pronoun can substitute not only the names of people and objects, but also the names of actions that are formed with nouns. An object form corresponds to entire situations. The subject pronoun can be substituted with a coreferent name. The verb construction cannot be put in a position occupied by an object pronoun. In this position, it should only be represented in the form of a 'nominalized' infinitive, a gerundial construction with an article and conjunctions. An utterance containing an object pronoun is a complex construction with two predicate units - the major one and the dependent one expressed by a pronoun. The meaning of a pronoun and the meaning of a verb with which the pronoun forms a pronominal group are consistent with each other. This consistency is expressed primarily in the fact that the pronoun agrees with verbs of a certain semantics; personal pronouns that substitute the person in the position of the subject usually form a group with action verbs; object pronouns related to the predicate structure most commonly correlate with verbs that convey specific or temporary characteristics of the action, with evaluative constructions, as well as with propositional verbs.

Certain verbs correlate with names of people and objects, as well as with names of events, and, accordingly, with subject or object pronouns that substitute them. However, these pronouns differ in their role in a verb construction. In the construction 'je le vois', the pronoun ' $l e$ ' could denote 'him' and 'it', and substitutes of names and objects are more clearly associated with the semantics of the verb than substitutes of events in the example ' $l e$ ' - 'him' means someone who I see. In the second case, it could denote any phrase.

Therefore, pronouns cannot be called 'empty' words that acquire a meaning in a sentence in connection with other words. Pronouns have their own signifier, which can be represented as a combination of differential features that reflect various aspects of the functioning of pronouns.

Pronouns can be regarded as content words that have a contextual feature, i.e., expressing a relation to the center of a speech situation. Pronouns convey an extremely specific meaning. This meaning is lexical by the fact that, in inflected languages, it is expressed by a root of a word, which could be combined with affixes. The distinctiveness of a lexical meaning of pronouns is defined by the nature of the part of the verbalized logical operations that they represent in the system of parts of speech. This also explains the coincidence of this meaning with the categorical meaning of this class of words, since a relation to the center of the speech situation can only be represented by itself.

In the system of parts of speech (consisting of three levels: independent entities, qualities, and qualities of qualities), pronouns are considered to be at the first level along with nouns and numerals. However, when viewed as expressions of special features of independent entities, pronouns belong to the second level. The same level include adjectives, verbs, and numerals.

Thus, pronouns represent the speaker and his/her interlocutor as the center of the speech situation and are able to express the 'contour and the object' in a given speech environment using the contextual feature. This opinion could be contrasted with the view, according to which, a large number of words should also be assigned to this category of words, for example, the particles 'yes', 'no', the adverbs 'on the contrary', 'now', 'tomorrow', if the contextual feature is considered to be the major distinctive feature of pronouns. In addition, a meaning of proper nouns is also determined by the entire situation in each particular case [8].

In semantic classification, the forms 'read, reads' do not express the category of the 
person who may be the speaker, the recipient, or the subject of communication, but the category of the person's communicative role in the speech process. Positioning the semantic meanings vertically, and grammar meanings horizontally, a pronoun is found to be at the intersection of these two lines. Expressing the relations between people in the process of speech, a pronoun is at the intersection of the two meanings, namely, lexical and grammatical.

The study of the communicative function of pronouns of the 1st and 2nd person allows to conclude that the forms 'we-you' can be either paired or unpaired, which is due to the relations between a person and a language in the process of speech communication. The major function of a pronoun is the deictic function. This denotes a special method of identification of the called subject, which necessarily implies a particular context.

The deictic meaning of 'we' includes the meaning of reciprocus - mutual participation in communication, $(\mathrm{I}+$ you $)$ and communis - joint participation in communication (I+he).

The pronominal form 'you' conveys the meaning 'potential involvement in communication indicating the recipient(s) in the form of a real participation in the conversation and specifying the recipient(s) together with potential participants of the conversation.

In the meaning 'communis' - the pronouns 'we-you' are paired, and in the meaning 'reciprocus' - they are unpaired. The personal pronoun 'they' has two deictic meanings: potential participation in communication and non-participation in communication, i.e. reference to the subject. Pronouns convey semantics and act as elements of a semantic structure, which denotes a way of expressing the grammatical category of person/subject and object by the system of pronouns in the formulas of a two-member sentence. The semantic structure is formed through the connection of their function and form. The deictic meanings of the personal pronouns 'we-you' are symmetrical in indicating the form of joint involvement of real and potential participants of communication: we $=\mathrm{I}+$ he $(\mathrm{she})$, you $=$ you (youthe (she). They are asymmetric in indicating the form of joint real participation in communication: the indication of the form of joint real participation is peculiar only to the pronoun we $=\mathrm{I}+\mathrm{you}$, whereas the pronoun 'you' does not convey this meaning.

The symmetry of the deictic meanings of the pronouns 'we' and 'you' is explained by the common positions of the speaker and the recipient in the form of joint potential participation in speech activity (the form of communis). The asymmetry of the deictic meanings of the pronouns 'we' and 'you' is determined due to the difference in the positions of the speaker and the recipient in the form of joint real participation in communication (the form of reciprocus). Characteristics of speech activity of the speaker and the recipient in the form of joint participation in communication is fundamentally different: only the speaker who is included in every act of speech is the real participant of communication, while the recipient is a potential participant of communication, the exclusive position of which is identical to the position of a person speaking the language, but not participating directly in the act of communication.

\section{Conclusion}

The study of personal pronouns in Western and Eastern European languages in order to determine their grammatical essence and pragmatic communicative function has demonstrated that, depending on the approach, pronouns are defined as 'substitutes' (from Latin: substituo - I place instead of), which replace the corresponding name. Within this meaning of a pronoun, the definition correlates with its Latin name. In the definition of a pronoun as 'deixis' (from Greek déixix - reference), the meaning of a representative symbol and a function, as well as the references to people, objects or events that are in relation to the speaker or the moment of speech, are in the foreground. 
Based on the criterion of mandatory use of personal pronouns, they are divided into according to the degree of analytism of their grammatical structure, rather than into Western/Eastern European languages. Thus, in the English, French, German languages, the conjugated verb must be accompanied with a personal pronoun, while in Spanish, Italian (the immediate successor of Latin) and Russian, a pronoun can be omitted when the verb is used.

A pronoun plays an important role in the formation of a text, performing the speech-language function of substitution and reference to the situation and participants of the communicative act.

\section{Discussion}

The problems of ambiguity and contradictions in the definition of a pronoun are solved when the purpose of the research and the approach to the study are taken into account. Considering a pronoun as an element of the language system, it can be defined as a substitute of a name by using the Latin calque ('substituo'), or as a stylistic repetition using the Greek calque ('anaphora'). When focusing on the pragmatic communicative function of a pronoun, the definition is based on regarding a pronoun as a deictic element ('deixix') [9].

The consideration of pronominal forms of politeness in the phatic function requires separate consideration. A quick glance suggests that the use of different pronominal forms of politeness in sister languages (Roman) can be explained by the customary use or adherence of Italian and Spanish to the Latin traditions [10]. Thus, the polite form of address is conveyed in Russian with the form ' $B b l$ ' - the 2 nd person pl., in French - with the pronoun 'Vous' - the 2nd person pl., in English - also with the form of the 2nd person 'You', in Italian - except for the form ' $V o i$ ' - the 2nd person pl., also with the forms 'Lei', 'Ella' - the 3rd person sing., 'Loro' - the 3rd person pl., in Spanish - with the forms of the 3rd person sing. ' $U d$ ' and pl. ' $U d s$ ', in German - with 'Sie' - the form of the 3rd person pl. According to the criterion - the use of the pronominal form of politeness - the division of languages into Western /Eastern European type is invalid.

\section{Conclusions}

The research results demonstrate that in the modern Russian and foreign linguistics, there is no single criterion for determining the grammatical essence and status of pronouns in different languages. In all languages, a pronoun is considered to be a separate part of speech, and moreover, pronouns catalyze the syntactic functions of a verb. The meaning of a pronoun and the meaning of a verb with which the pronoun forms a pronominal group are consistent with each other. A pronoun is an actualizer of a verbal semanteme, its connection with the verb is necessary and inextricable. In addition, a pronoun could be defined as a noun substitute, which could be used in an anaphoric function. The criteria of mandatory use of personal pronouns are not determined by the principle of division into Western / Eastern European languages, but by the degree of analytism of their grammatical structure. A pronoun plays an important role in the formation of a text, performing the speech-language function of substitution and reference to the situation and participants of the communicative act. Many questions related to the study of the formation and syntactic functions of pronouns require more in-depth research involving data obtained from languages of other families and ancient deciphered languages.

\section{References}

1. L. Bloomfield, Language (Moscow, 2015) https://www.studmed.ru/blumfild-l-yazyk_ 
7505c26f7ac.html

2. G. Moignet, Toward a Typology of European Languages (Berlin, New York, 1990)

3. R. Jacobson, Essai de linguisique generale (2003) http://www.leseditionsdeminuit.fr/livre-Fondations_du_langage._Essais_de_linguistiqu e_g\%C3\%A9n\%C3\%A9rale_I\%C2\%A0_(Les)-2137-1-1-0-1.html

4. G.A. Zolotova, Voprosy iazykoznaniia 2 (1995)

5. V.G. Gak, Teoreticheskaia grammatika frantsuzskogo iazyka (2000)

6. M.Ia. Blokh, Teoreticheskie osnovy grammatiki (Moscow, 2000)

7. A.V. Isachenko, Grammaticheskii stroi russkogo iazyka (Moscow, 2003)

8. E.V. Korpusova, Pragmaticheskii aspekt roli govoriashchego $v$ funktsional'no-smyslovykh tipakh rechi «opisanie» $i$ "povestvovanie» diss.kan.fil.n (Kemerovo, 2003)

9. A.B. Alferov, Interaktsional'nyi deiksis. Interaktsional'nyi deiksis kak sredstvo organizatsii rechevogo vzaimodeistviia: Na materiale frantsuzskogo iazyka, diss.d-ra fil. nauk (Piatigorsk, 2001)

10. I.A. Bolshakov, Vyrazhenie uvazhitel'nosti s pomoshch'iu lichnykh mestoimenii v riade evropeiskikh iazykov (Moscow, 2001) 